\title{
Beta Cell Function, Insulin Resistance and Low Grade Systemic Inflammation in Myanmar Adults with Different Categories of Glucose Tolerance
}

\author{
Mo-Mo-Than, ${ }^{1}$ May Thazin, ${ }^{2}$ Tint Swe Latt ${ }^{3}$ \\ ${ }^{1}$ Department of Biochemistry, Defence Services Medical Academy, Yangon, Myanmar \\ ${ }^{2}$ Department of Biochemistry, University of Medicine 2, Yangon, Myanmar \\ ${ }^{3}$ Rector, University of Medicine 2, Yangon, Myanmar
}

\begin{abstract}
Objective. The aim of the study was to evaluate the beta cell function, insulin sensitivity and low grade systemic inflammation in different categories of glucose tolerance in Myanmar.

Methodology. A cross-sectional study was conducted on 202 Myanmar subjects of both sexes, aged between 45-65 years old. Fasting blood glucose, insulin, C-peptide and hs-CRP levels were measured. A $75 \mathrm{~g}$ oral glucose tolerance test was performed. Insulin resistance and beta cell function were assessed by homeostasis-model-assessment (HOMA).

Results. The subjects were categorized as normal glucose tolerance (NGT), impaired fasting glucose (IFG), impaired glucose tolerance (IGT) and diabetes mellitus (DM) according to WHO-2006 criteria. Fasting serum insulin, C-peptide and hs-CRP levels and insulin resistance index (HOMA-IR) progressively increased from NGT through prediabetes (IFG, IGT) to DM $(p<0.01)$. Beta-cell function did not change significantly in any other group as compared to normal group.

Conclusion. After multivariate analysis, increases in fasting C-peptide, hs-CRP and HOMA-IR index were significantly associated with diabetes. It was also found that insulin resistance was a predominant feature in deterioration of the glucose tolerance in Myanmar subjects.
\end{abstract}

Key words: beta cell function, diabetes mellitus, insulin resistance, glucose intolerance, Myanmar

\section{INTRODUCTION}

Population growth, aging, urbanization and increasing prevalence of obesity and physical inactivity are generally regarded as contributing factors for the rising prevalence of diabetes mellitus (DM). The total number of people with DM is projected to rise from 171 million in 2000 to 366 million in 2030. ${ }^{1}$ Urbanization is associated with changes in lifestyle. Physical inactivity, unhealthy diet and obesity have been implicated as contributing factors for rapid development of type 2 diabetes mellitus (T2DM). 2,3 In Myanmar, the prevalence rates of DM and combined IFG and IGT (prediabetes) were 11.8\% (95\%CI-10.1, 13.4\%) and $13.4 \%$ ( 95\% CI-12.0, 14.8\%) respectively. ${ }^{4}$

The natural history and pathogenesis of T2DM indicate that this disease has a prolonged prediabetic phase. ${ }^{5}$ Consequently, there is an opportunity to identify patients at high risk for developing diabetes and institute primary prevention strategies. Patients with prediabetic states, which include IFG and IGT, are at significant risk for

ISSN 0857-1074

Printed in the Philippines

Copyright $(2013$ by the JAFES

Received March 25, 2013. Accepted April 23, 2013. development of diabetes. Compared with normoglycemic persons, patients with IFG and IGT are frequently associated with metabolic syndrome. ${ }^{6}$

One important factor that is usually associated with glucose intolerance is hyperinsulinemia. This relationship is thought to be mediated by insulin resistance. Although both fasting insulin and fasting $\mathrm{C}$-peptide have been employed as a measure of insulin resistance, C-peptide is not metabolized by the liver and is therefore a more reliable index of pre-hepatic insulin than the fasting insulin. Therefore, C-peptide measurement has been used as an alternative, reliable surrogate for assessing pancreatic insulin secretion. Elevated C-peptide level has been shown to precede the development of T2DM in Japanese American men.?

The homeostatic model assessment (HOMA) is a validated method to measure insulin resistance from fasting glucose and insulin. The original model HOMA1-IR, first published by Matthews et al in 1985, has been widely

Corresponding author: Mo Mo Than, MBBS

Lecturer/ Head, Department of Biochemistry

Defence Services Medical Academy

No. 94, Pyae Road, Mingaladon Tsp, Yangon, Myanmar

Tel. No.: +9531-35067, +9595-143107

Fax No.: +951-635071

E-mail:momomoekyaw@gmail.com 
used. ${ }^{8}$ The model was subsequently updated with some physiological adjustments to a computer version (HOMA2-IR) providing a more accurate index. ${ }^{9}$ Onishi et.al., found that lower HOMA- $\beta$ and higher HOMA-IR are significant risk factors for the future development of prediabetes among Japanese with normal glucose tolerance. ${ }^{10}$

Chronic systemic inflammation can induce insulin resistance. Type 2 Diabetes is a manifestation of an ongoing acute phase response that is primarily characterized by alterations of the acute phase protein, such as C-reactive protein (CRP). CRP is an acute-phase reactant synthesized in the liver in response to cytokines, especially interleukin-6 (IL-6). In epidemiological studies, circulating CRP levels significantly predict the risk of T2DM. ${ }^{11}$ There is still controversy about whether lowgrade inflammation is an intermediate factor between obesity and insulin resistance or whether it has an independent effect on the development of T2DM through a mechanism separate from obesity. Niehoff et. al., also reported that CRP was not related to insulin resistance after adjustment for parameters of body composition. ${ }^{12}$ However, data on CRP and diabetes are limited in Asia. ${ }^{13}$ Thus, CRP might provide an adjunctive measure for identifying subjects with the highest risk of progression to diabetes who would derive the greatest benefits from preventive measure.

Most important, insulin resistance has been associated with increased cardiovascular risk and chronic subclinical inflammation in several populations. Predominant defect in beta cell function or insulin resistance appears to differ among ethnic groups. ${ }^{14}$ Therefore, this study was conducted to evaluate the beta-cell function, insulin resistance and low-grade inflammation in adults with different categories of glucose tolerance in Myanmar.

\section{METHODOLOGY}

This cross-sectional study included a total of 202 Myanmar subjects (aged 45 to 65 years, 71 males and 131 females) who lived in an urban area of Yangon, Myanmar. The subjects were selected by the two-stage sampling procedure.

\section{First stage sampling procedure}

Out of 45 townships in Yangon Region, Mingalar-TaungNyunt Township is one of the urban areas in Yangon. Then 7 wards from Mingalar-Taung-Nyunt Township were selected by simple random sampling method.

\section{Second stage sampling procedure}

From each selected ward, adults with eligible criteria were selected according to the probability proportionate to the size of these wards. Subjects were excluded from the study if they were known to have diabetes, any disease and medication that might influence glucose metabolism. This research was approved by the institutional ethical committee review board, and signed informed consent was obtained from all participants. The clinical examination consisted of a medical history, physical examination, and anthropometric measurements (height, weight and BMI). Plasma glucose, insulin, C-peptide and hs-CRP were measured after an overnight 10 -h fast and then the subjects underwent a 75-g oral glucose tolerance test. The glucose tolerance was classified according to the WHO (2006) criteria ${ }^{15}$ for fasting and 2-hr glucose levels. Plasma glucose levels were determined by glucose oxidase method with Humalyzer 2000 (Human, Wiesbaden, Germany).The serum insulin, C-peptide and hs-CRP were determined by ELISA methods with EIA-2935, EIA-1293 and EIA-4584 of DRG, Germany respectively. Insulin resistance and beta cell function were assessed by homeostasis model assessment (HOMA2-IR and HOMA2$\beta)$ by HOMA-2 calculator model. ${ }^{16}$ Body mass index (BMI) was calculated as the weight in kilograms divided by the height in meters squared.

Statistical analyses were performed using computer-based Statistical Product and Service Solutions (SPSS) software version 16.0 and descriptive statistics of numerical variables were expressed as mean \pm SD. Description of categorical variables was expressed as percentage. Comparisons among groups were analyzed by analysis of variance (ANOVA) test with Bonferroni method for continuous variables. Pearson's correlation analysis was used to determine the relationships between variables. Stepwise logistic regression was used to evaluate the significant factors associated with diabetes. A receiver operating characteristic (ROC) curve was used to determine the cutoff values. Level of significance was set at $\mathrm{p}<0.05$.

\section{RESULTS}

The baseline anthropometric and metabolic characteristics of the study groups across glucose tolerance levels are presented in table 1 . Out of the total 202 subjects, there were $111(54.95 \%)$ in NGT group, $10(4.9 \%)$ in IFG group, $31(15.35 \%)$ in IGT group and $50(24.75 \%)$ in DM group according to the WHO (2006) criteria. Nearly half the subjects in the study group have decreased glucose tolerance. The sex distribution of the present study showed that the females were the majority representing $64.9 \%$ of the study population. The DM group were older than NGT group $(\mathrm{p}<0.05)$. There were no significant differences between groups with regard to BMI and age. The mean BMI $(26.06 \pm 5.56)$ of the present study could be considered as overweight category (BMI $\geq 25 \&<30$ ) according to the standard BMI for Asians. ${ }^{17}$ In the present study, there was a large increase in proportion of prediabetes and T2DM as compare to the previous study in rural and urban areas of Yangon Division, Myanmar. ${ }^{4}$ This may be due to the lifestyle changes of urbanization. 
Table 1. Anthropometric and metabolic characteristics of subjects with different glucose tolerance categories

\begin{tabular}{|c|c|c|c|c|c|}
\hline & $\begin{array}{c}\text { NGT } \\
(n=111)\end{array}$ & $\begin{array}{c}\text { IFG } \\
(n=10)\end{array}$ & $\begin{array}{c}\text { IGT } \\
(n=31)\end{array}$ & $\begin{array}{c}\mathrm{DM} \\
(\mathrm{n}=50)\end{array}$ & $\begin{array}{l}\text { ANOVA } \\
p \text { value }\end{array}$ \\
\hline $\operatorname{Sex}(M / F)$ & $33 / 78$ & $3 / 7$ & $15 / 16$ & $20 / 30$ & \\
\hline Age (years) & $52.29 \pm 5.96$ & $54.20 \pm 6.96$ & $53.16 \pm 5.39$ & $55.20 \pm 6.47^{*}$ & \\
\hline $\mathrm{BMI}\left(\mathrm{Kg} / \mathrm{m}^{2}\right)$ & $26.07 \pm 5.29$ & $25.24 \pm 3.87$ & $25.77 \pm 5.11$ & $26.38 \pm 6.69$ & \\
\hline Fasting plasma glucose $(\mathrm{mmol} / \mathrm{L})$ & $4.31 \pm 0.00$ & $6.59 \pm 0.00$ & $5.27 \pm 1.10$ & $8.66 \pm 3.04$ & \\
\hline 2-hr plasma glucose $(\mathrm{mmol} / \mathrm{L})$ & $5.69 \pm 1.08$ & $5.88 \pm 1.00$ & $8.97 \pm 0.00$ & $14.44 \pm 3.92$ & \\
\hline Fasting insulin $(\mu \mathrm{IU} / \mathrm{mL})$ & $4.74 \pm 1.30$ & $7.31 \pm 2.75$ & $9.01 \pm 2.72$ & $13.1 \pm 7.44$ & $<0.01$ \\
\hline Fasting C-peptide (ng/mL) & $1.05 \pm 0.45$ & $1.88 \pm 0.77$ & $2.14 \pm 0.84$ & $2.75 \pm 1.35$ & $<0.01$ \\
\hline Fasting hs-CRP (mg/L) & $3.76 \pm 2.91$ & $5.20 \pm 5.56$ & $6.94 \pm 3.95$ & $11.34 \pm 7.13$ & $<0.01$ \\
\hline HOMA2-IR & $0.62 \pm 0.30$ & $1.01 \pm 0.35$ & $1.16 \pm 0.38$ & $1.91 \pm 1.15$ & $<0.01$ \\
\hline HOMA2 - $\beta$ & $113.0 \pm 41.23$ & $69.26 \pm 19.4$ & $139.9 \pm 71.64$ & $79.75 \pm 68.64$ & $<0.01$ \\
\hline
\end{tabular}

The prevalence of diabetes in Asian populations has increased rapidly in recent decades.

The study of Tint-Swe-Latt et al., ${ }^{19}$ in 2004 reported that diabetes mellitus is by far the most common metabolic disorder in Myanmar. Therefore, the increased prevalence of prediabetes and diabetes obtained in the present study firmly supported that prevention and control of diabetes should be a top public health priority in Myanmar.

The mean fasting insulin, C-peptide and hs-CRP levels progressively increased from NGT through prediabetes to the newly diagnosed diabetes $(p<0.01)$. The mean fasting insulin level of DM group was significantly higher than NGT, IFG, IGT groups and the level of IGT was significantly higher than that of NGT $(p<0.01)$.It could be explained by the higher level of insulin resistance and a consequent compensatory increase in beta cell mass and hypertrophy of existing beta cells to meet the increased demand and to avoid more severe hyperglycemia. ${ }^{20}$ Reasner $(2010)^{21}$ also discussed that the initial defect in the pathogenesis of diabetes is insulin resistance, but the body is able to overcome this defect for a period through increased insulin production. According to the above reason, the mean fasting insulin levels in IGT and DM group were 1.9-fold and 2.8-fold compared with the levels in NGT group respectively in the present study.

Human C-peptide provides an accurate assessment of residual beta-cell function and thus has been widely used as a marker of insulin secretion in patients with diabetes. ${ }^{22}$ In the present study, like fasting insulin level, the mean fasting C-peptide level in DM group was significantly higher than NGT, IFG, IGT groups and the level of IGT as well as IFG was significantly higher than that of NGT group $(\mathrm{p}<0.05)$. Therefore, the current study highlighted the fact that fasting $\mathrm{C}$-peptide gave the more accurate discrimination than the fasting insulin in assessing insulin secretion and high C-peptide levels have been interpreted as representing hypersecretion of insulin as a compensatory response to insulin resistance.The mean fasting hs-CRP level in DM group was also significantly higher than NGT, IFG, IGT groups and the level of IGT was significantly higher than that of NGT $(p<0.05)$. The trend of increase in mean fasting hs-CRP levels of the present study was nearly similar to those found in other studies ${ }^{23-26}$ and it could also be explained by progression of low-grade inflammation as a potential dynamic in pathogenesis of T2DM. Snijder et al., in the Hoorn study also stated that CRP level progressively increased as the glucose metabolism deteriorates. ${ }^{27}$ Ridker et al., also stated that CRP was an important predictor of T2DM. ${ }^{28}$ In the Hong Kong cardiovascular risk factor prevalence study, subjects with IGT with the highest CRP concentration were at three-fold risk of either remaining in IGT or progressing to diabetes compared to subjects with lowest CRP concentration. ${ }^{23}$ In the Hisayama study in Japan, increased CRP level was a significant predictor of incident diabetes in both gender of the general Japanese population. ${ }^{29}$

With regard to insulin resistance, there was also progressive increase in HOMA2-IR across the glucose tolerance levels $(p<0.01)$. The mean HOMA-IR in DM group was significantly higher than that of NGT, IFG, IGT groups and the mean HOMA-IR of IGT was significantly higher than that of NGT $(p<0.01)$. The HOMA2-IR is a more accurate representation of the metabolic process because it models the feedback relationship between insulin and glucose in the various organs in the body. ${ }^{30}$ Therefore, the current study used the HOMA-2 computer model in which the mean fasting insulin level is used to compute HOMA2-IR which determines the resistance to insulin action, and C-peptide is used to compute HOMA2$\AA$ which determines pancreatic insulin secretion. There was a marked increase in HOMA2-IR with the deterioration of glucose tolerance. The magnitude of the incremental increase in HOMA2-IR in subjects with IFG, IGT, and DM groups was 1.6-, 1.9-, and 3.1- fold greater than in subjects with NGT respectively. The findings of the present study concerning HOMA2-IR were comparable with the previous Asian studies. ${ }^{31,32}$ However, the HOMA2-IR indices of other studies ${ }^{33,34}$ were higher than those of the present study. These equivocal and conflicting findings can be explained by differences in study populations, study designs, methods to assess insulin resistance and insulin secretion by HOMA-IR (i.e., HOMA1-IR or HOMA2-IR), different cut-off points in categorization of glucose tolerance and ethnic differences. The ethnicity difference statement was supported by 
findings of previous studies. ${ }^{14,35,36}$ Amoah et al., also discussed that race and ethnicity, independent of family history, also determine insulin resistance in several populations. ${ }^{14}$ Insulin resistance, whether genetically inherited or acquired, could precipitate the development of IGT and T2DM. Stancakova et al., showed in a large cohort study of Finnish men that peripheral insulin resistance started at relatively low plasma glucose levels within normoglycemic range and is the predominant feature of isolated IGT, whereas impairment in early and total insulin release characterizes isolated IFG. ${ }^{37}$ Taken together, the present study suggested that insulin resistance along with elevated insulin levels could precipitate the development of prediabetes (IFG, IGT) and T2DM.

As for the beta cell function as assessed by HOMA2- $\beta$, there was no significant change in HOMA2- $\beta$ in all glucose tolerance categories when compared to NGT. However, there was significant decline in beta-cell function in IFG and DM groups as compared to IGT groups $(\mathrm{p}<0.01)$. The same patterns of changes in HOMA- $\beta$ were found in other international studies. ${ }^{37,38}$ However, a large reduction in beta-cell function in both prediabetes and diabetes had been observed in Japanese and other groups. ${ }^{10,39,40}$

The variance between the present study and previous studies may also be due to ethnic differences, different assessing methods in insulin secretion and different ranges of BMI in each study group. Even among the Asian countries, there were variations in beta-cell function at different stages of glucose tolerance. A South Indian study stated that insulin resistance is manifested in the early stages of glucose tolerance and beta-cell defect was mostly found in diabetes. ${ }^{41}$ Fukushima et al., from Japan study found that decreased basal and early-phase insulin secretion had more pronounced contribution to glucose tolerance than insulin resistance. ${ }^{32}$ However, a Pakistan study reported that IFG and DM groups had low insulin secretion while IGT group had high insulin secretion as compared to DM. ${ }^{42}$ A Thai study also found that subjects with IFG and DM had a significantly lower beta-cell function than those with IGT. ${ }^{31}$

Stancakova et al., explained that individuals with IFG have impairment in both basal and glucose stimulated insulin release, whereas individuals with IGT have increased basal and total insulin release. ${ }^{37}$ Festa et al., reported that the relationship between glucose and insulin in the basal state reflects the balance between hepatic glucose output and insulin secretion, which is maintained by feedback loop between the liver and beta cells and concluded that the potential limitations of the use of HOMA- $\beta$ include its lack of capture of stimulated state by relying on fasting measures, and its insensitivity to a variable $\beta$-cell glycemic sensitivity. ${ }^{38} \mathrm{Ning}$ et al., discussed that both HOMA-IR and HOMA- $\beta$ are only surrogate indicators of insulin sensitivity and beta-cell function which are mainly based on glucose and insulin levels at the fasting state. ${ }^{43}$ They do not directly reflect the capacity of the beta cell to cope with the glucose challenge and thus may be less associated with IGT. This explanation was applicable to the present finding with high HOMA- $\$$ in IGT group because IGT is characterized by elevated 2-hour glucose level with normal fasting glucose level with elevated insulin level as a compensatory effect.

Table 2 shows the correlation between serum C-peptide, hs-CRP, BMI, serum insulin, HOMA2-IR and HOMA2- $\beta$. In the study population, BMI correlated positively with hsCRP. Fasting serum insulin correlated positively with fasting serum C-peptide, hs-CRP and HOMA2-IR. Fasting serum C-peptide correlated positively with fasting serum insulin, hs-CRP and HOMA2-IR. Fasting serum hs-CRP also correlated positively with BMI, fasting serum insulin, fasting C-peptide and HOMA2-IR $(\mathrm{p}<0.01)$. The fasting hsCRP was significantly negatively correlated with HOMA2$\beta$ ( $\mathrm{p}<0.05)$. Marx et al., had explained that $\mathrm{C}$-peptide might deposit in the vessel wall in patients with insulin resistance and early T2DM and C-peptide deposition is mainly in the subendothelial space and the intima. ${ }^{44}$ Higher C-peptide deposition leads to endothelial dysfunction and release of cytokines and chemotactic proteins and expresses adhesion molecules on the endothelial cell surface. Such mechanism supported the present finding that the C-peptide was strongly correlated with hs-CRP. In addition, low grade systemic inflammation is considered an important mechanism leading to obesity, insulin resistance and T2DM. Ford et al, Festa et al., and Vikram et al., reported that there was significant correlation between inflammatory markers like CRP and fasting insulin as well as BMI. ${ }^{45,46,47}$ Woperies et al., reported that inflammatory modulation may alter insulin signaling in overweight men. ${ }^{48}$ Reasner also discussed that high insulin level and impaired insulin signaling may contribute to the development of macrovascular complications in T2DM. ${ }^{20}$ In healthy individuals, when glucose enters the cell via glucose transporters, it stimulates nitric oxide production. Nitric oxide is a potent vasodilator and improves endothelial function. Persons with insulin resistance have less glucose entering their cells, and therefore less nitric oxide stimulation. As the body makes more insulin to compensate for higher circulating glucose levels, the excess insulin stimulates the MAP kinase pathway. The MAP kinase signaling pathway ultimately promotes inflammation, cell growth/proliferation, and finally, atherosclerosis. The combination of above mechanisms supported the present finding with strong positive correlation of hs-CRP and BMI, fasting insulin, C-peptide, and HOMA-IR indices.

In the present study, stepwise logistic regression (Table-3) showed that the serum C-peptide, hs-CRP levels and HOMA2-IR were strongly associated with diabetes. 
Table 2.Correlation between serum C-peptide, hs-CRP, and BMI, serum insulin, HOMA2-IR and HOMA2- $\beta$

\begin{tabular}{|c|c|c|c|c|c|c|c|c|c|c|c|c|}
\hline \multirow{2}{*}{ Parameters } & \multicolumn{2}{|c|}{ BMI $\left(\mathrm{Kg} / \mathrm{m}^{2}\right)$} & \multicolumn{2}{|c|}{ insulin $(\mu \mathrm{IU} / \mathrm{mL})$} & \multicolumn{2}{|c|}{ C-peptide (ng/mL) } & \multicolumn{2}{|c|}{ hs-CRP (mg/L) } & \multicolumn{2}{|c|}{ HOMA2-IR } & \multicolumn{2}{|c|}{ HOMA2 - $\beta$} \\
\hline & $r$ & $P$ & $R$ & $p$ & $r$ & $p$ & $\mathbf{R}$ & $P$ & $r$ & $p$ & $\mathbf{R}$ & $P$ \\
\hline $\mathrm{BMI}\left(\mathrm{Kg} / \mathrm{m}^{2}\right)$ & & & 0.12 & 0.10 & 0.11 & 0.11 & 0.20 & $<0.01$ & 0.10 & 0.15 & 0.04 & 0.62 \\
\hline insulin $(\mu \mathrm{lU} / \mathrm{mL})$ & 0.12 & 0.10 & & & 0.82 & $<0.01$ & 0.53 & $<0.01$ & 0.96 & $<0.01$ & -0.08 & 0.27 \\
\hline C-peptide (ng/mL) & 0.11 & 0.11 & 0.82 & $<0.01$ & & 1 & 0.48 & $<0.01$ & 0.80 & $<0.01$ & -0.04 & 0.53 \\
\hline $\mathrm{hs}-\mathrm{CRP}(\mathrm{mg} / \mathrm{L})$ & 0.20 & $<0.01$ & 0.53 & $<0.01$ & 0.48 & $<0.01$ & & & 0.49 & $<0.01$ & -0.15 & $<0.05$ \\
\hline
\end{tabular}

Table 3. Stepwise logistic regression of independent variables associated with type 2 diabetes mellitus

\begin{tabular}{lccc}
\hline \multirow{2}{*}{$\begin{array}{c}\text { Independent } \\
\text { Variable }\end{array}$} & \multicolumn{3}{c}{ Dependent Variables } \\
& Diabetes & vs Non-Diabetes \\
\hline BMI $\left(\mathrm{Kg} / \mathrm{m}^{2}\right)$ & 0.93 & $0.85-1.02$ & 0.13 \\
Insulin $(\mu \mathrm{IU} / \mathrm{ml})$ & 0.99 & $0.74-1.32$ & 0.92 \\
$\mathrm{C}-$ peptide $(\mathrm{ng} / \mathrm{ml})$ & 2.31 & $1.10-4.86$ & $<0.05$ \\
hs-CRP $(\mathrm{mg} / \mathrm{L})$ & 1.15 & $1.02-1.31$ & $<0.05$ \\
HOMA2- IR & 12.84 & $2.25-73.46$ & $<0.01$ \\
\hline Cl means confidence interval & & &
\end{tabular}

Among which, HOMA2-IR (odds ratio, OR = 12.84) was more strongly associated with diabetes than that of serum C-peptide and hs-CRP level.

It can be concluded that insulin resistance is the predominant feature in the deterioration of glucose tolerance in the present study. Moreover, one of the great opportunities is to specify the cut-off values of HOMA2IR, fasting serum C-peptide and hs-CRP for predicting diabetes in Myanmar. According to the ROC curve, the cut-off value in predicting T2DM for HOMA2-IR was 1.05 (88\%-sensitivity and $84 \%$-specificity), C-peptide was 1.85 $\mathrm{ng} / \mathrm{ml}$ (82\%-sensitivity and $81 \%$-specificity) and hs-CRP was $5.65 \mathrm{mg} / \mathrm{L}$ (76\%-sensitivity and 70\%-specificity) according to ROC curve (Figure 1).

There are several limitations in the present study. First, the study was a cross-sectional study and it cannot conclude cause-effect relationships. Therefore, it cannot evaluate the beta-cell secretory function and insulin sensitivity associated with progressive deterioration of glucose tolerance in development of prediabetes as well as diabetes in Myanmar population. Second, the present study used HOMA method to assess the beta-cell function and it is mainly based on glucose and insulin levels at the fasting state. However, the dynamic properties of $\beta$-cell function provides a better index of $\beta$-cell ability to increase insulin release in appropriate amount and time course to cope with acute change in plasma glucose concentration. Further confirmatory studies are needed to clarify the $\beta$ cell function under dynamic state in different glucose tolerance states. Third, the present study was focused on clinical measurements and it did not include the information on behavioral practices and environmental stressor concerning varying glucose intolerance. Fourth, this study reported the data of small number of patients particularly of the IFG group, although the results were in agreement with some international studies. On the other hand, this study was a pioneer study analyzing the insulin resistance and insulin secretion at different levels of glucose tolerance in the Myanmar subjects, resulting into generation of baseline data for further studies to be done among Myanmar population.

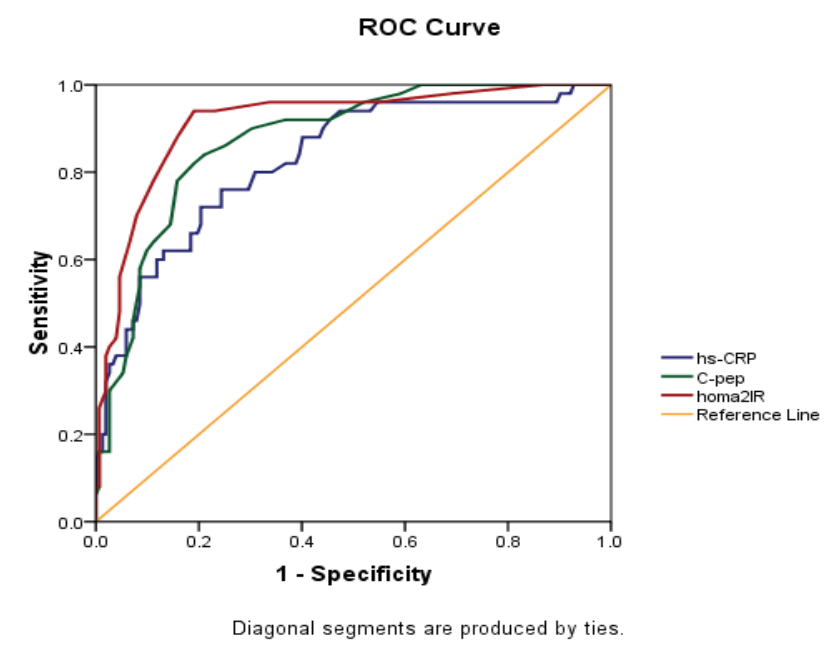

Figure 1.ROC Curve of hs-CRP, C-peptide, HOMA2-IR for predicting newly- diagnosed diabetes

Cut-off value for hs-CRP-5.65mg/L (AUC-0.828)

(Sensitivity - 0.76, Specificity - 0.70)

Cut-off value for C-pep-1.85 ng/ml (AUC-0.874)

(Sensitivity - 0.820, Specificity - 0.809)

Cut-off value for HOMA-IR-1.05(AUC-0.915)

(Sensitivity - 0.88, Specificity - 0.84)

\section{CONCLUSION}

Beta-cell function deterioration was found in prediabetes and DM group. Within the prediabetic group, IFG subjects had elevated fasting plasma glucose levels because of impaired insulin secretion, whereas the fasting plasma glucose concentrations in IGT subjects were regulated by a compensatory increase in insulin concentration. Therefore, the present study supported the notion that subjects with IFG and IGT differ with respect to beta-cell dysfunction. After multivariate analysis, increased fasting C-peptide, hs-CRP and HOMA-IR index were significantly associated with diabetes. It was also found that insulin resistance was a predominant feature in deterioration of the glucose tolerance in Myanmar subjects. Moreover, one of the great opportunities is to specify the cut-off values of HOMA2-IR, fasting serum Cpeptide and hs-CRP for predicting diabetes in Myanmar. These findings need to be confirmed by more large-scale studies in urban as well as rural areas of Myanmar. 


\section{References}

1. Wild S, Green A, Sicree R. Global prevalence of Diabetes. Estimates for the year 2000 and projections for 2030. Diabetes Care. 2004; 27: 1047-1053.

2. Kaku K. Pathophysiology of type 2 Diabetes and its treatment policy. JMJ.2010; 53: 41-46.

3. Yang W, LU J, Weng J, et al. For the China National Diabetes and Metabolic Disorders Study Group.Prevalence of Diabetes among men and women in China.N Engl J Med. 2010; 362: 1090-1101.

4. National Health Plan/Myanmar. Prevention and Control of Diabetes Mellitus, situational analysis,(2006-2011) 2-4.

5. Ramlo-Halsted BA, Edelman SV. The natural history of type 2 diabetes.Implications for clinical practice. Prim Care.1999; 26: 771-789.

6. Rao SS, Disraeli P, McGregor T. Impaired Glucose Tolerance and Impaired Fasting Glucose. Am Fam Physician. 2004; 69: 1961-1972.

7. Bergstrom RW, Leonetti DL, Newell-Morris LL, et al. Association of plasma triglyceride and C-peptide with coronary heart disease in JapaneseAmerican men with a high prevalence of glucose intolerance. Diabetologia. 1990; 33: 489-496.

8. Matthews D, Hosker J, Rudenski A, et al. Homeostasis model assessment: insulin resistance and beta cell function from fasting plasma glucose and insulin concentrations in man. Diabetologia.1985;28: 412-419.

9. Levy JC, Matthews DR, Hermans MP. Correct homeostasis model assessment (HOMA) evaluation uses the computer program (Letter). Diabetes Care. 1998; 21: 2191-2192.

10. Onishi Y, Hayashi T, Sato KK, et al. Fasting tests of insulin secretion and sensitivity predict future prediabetes in Japanese with normal glucose tolerance. Journal of Diabetes Investigation. 2010; 1: 191-195.

11. Pradhan AD, Manson JE, Rifai N, et al. C-reactive protein, interleukin 6 , and risk of developing type 2 diabetes mellitus. JAMA. 2001; 286: 327-334.

12. Niehoff AG, Haeften TW, Onland-Moret NL, et al. C-reactive protein is independently associated with glucose but not with insulin resistance in healthy men. Diabetes Care. 2007; 30: 1627-1629.

13. Nabipour I, Vahdat K, Jafari SM, et al. Elevated high sensitivity C-reactive protein is associated with type 2 diabetes mellitus: The Persian Gulf healthy heart study. Endocrine Journal. 2008; 55: 717-722.

14. Amoah AG, Schuster DP, Gaillard T, et al. Insulin Resistance, B-cell function and cardiovascular risk factors in Ghanians with varying degree of glucose tolerance. Ethnicity\& Disease. 2002; 12: 10-17.

15. WHO. Report of a WHO/IDF consultation: Definition, diagnosis and classification of diabetes mellitus and intermediate hyperglycemia. Geneva. 2006, 7-9. http://www.who,int/diabetes/. Accessed- November 18, 2010.

16. Holmen R, Hines G, Kenneday I, et al. A calculator for HOMA .Diabetologia. 2004; 47: suppl 1: A222. www.dtu.ox.ac.uk/homa. AccessedDecember 10,2010.

17. WHO/IASO/IOTF. The Asia-Pacific perspective: Redefining obesity and its treatment. Health Communications Australia, Melbourne,2000.

18. Chan JCN, Malik V, Jia W, et al. Diabetes in Asia; Epidemiology, risk factors and pathophysiology. JAMA. 2009; 301: 2129-2140.

19. Tint-Swe-Latt, Phyu-Phyu-Aung, Ko-Ko-Zaw, et al. Adult prevalence of diabetes mellitus and its sociodemographic, behavioral and physiological risk factors in Yangon Division. Paper of Myanmar Health Research Congress, Department of Medical Research. 2004.

20. Efrat S. Prospects for treatment of type 2 diabetes by expansion of the betacell mass. Diabetes 2001; 50(Suppl 1):S189-S190.

21. Reasner CA. What causes microvascular and macrovascular complications in patients with type 2 diabetes? Curriculum in: Type 2 Diabetes Mellitus in Practice. Projects In Knowledge \&Medpage Partners in Diabetes Education. 2010 [Accessed 17 March 2011]

22. Kjems LL, Volund A, Madsbad S. Quantification of beta-cell function during IVGTT in Type II and non-diabetic subjects: assessment of insulin secretion by mathematical methods. Diabetologia. 2001; 44: 1339-1348.

23. Kathryn CR, Nelson MS, Sidney CF, et al. C-reactive protein predicts the deterioration of glycemia in Chinese subjects with impaired glucose tolerance. Diabetes Care. 2003; 26: 2323-2328.

24. Henareh L, Jogestrandt T, Agewall S. Glucose intolerance is associated with C-reactive protein and intima-media anatomy of the common carotid artery in patients with coronary heart disease. Diabetic Medicine. 2005; 22: 1212-1217.

25. Ming-hui G, Jie H, An-kang L, et al.. High sensitive C-reactive protein, adiponectin, and urine albumin excretion rate in Chinese coronary artery disease patients with different glucose tolerance status. Chinese Medical Journal. 2008; 121: 2509-2516.

26. Ren J, Pang ZC, Gao WG, et al. C-reactive protein and gammaglutamyltransferase concentrations in relation to the prevalence of type 2 diabetes diagnosed by glucose or $\mathrm{HbA} 1 \mathrm{c}$ criteria in Chinese adults in Qingdao, China. Hindawi Publishing Corporation.Experimental Diabetes Research. Volume 2010; 10: 1155, 2010, 761715.

27. Snijder MB, Dekker JM, Visser JM, et al. Prospective relation of C-reactive protein with type 2 diabetes (Letter). Diabetes Care. 2003; 26: 1656-1657.
28. Ridker PM, Buring JE, Cook NR, et al. C reactive protein, metabolic syndrome and risk of incident cardiovascular events. Circulation. 2003; 107: 391-397.

29. Doi Y, Kiyohara Y, Kubo M, et al. Iida M. Elevated C-reactive protein is a predictor of the development of diabetes in a general Japanese population: The Hisayama study. Diabetes Care. 2005; 28: 2497-2500.

30. Wallace TM, Levy JC, Matthews DR. Use and abuse of HOMA modeling Diabetes Care. 2004; 27: 1487-1495.

31. Chailurkit L, Jongjaroenprasert W, Chanprasertyothin S, et al.. Insulin and C-Peptide Levels, Pancreatic Beta Cell Function, and Insulin Resistance Across Glucose Tolerance Status in Thais. Journal of Clinical Laboratory Analysis. 2007; 21: 85-90.

32. Fukushima $\mathrm{M}$, Usami $\mathrm{M}$, Ikeda $\mathrm{M}$, et al. Insulin secretion and insulin sensitivity at different stages of glucose tolerance: A cross-sectional study of Japanese type 2 diabetes. Metabolism 2004;53:831-835

33. Maki KC, McKenney JM, Farmer MV, et al. Indices of insulin sensitivity and secretion from a standard liquid meal test in subjects with type 2 diabetes, impaired or normal fasting glucose. Nutritional Journal. 2009; 8: $1-10$.

34. Sung K, Reaven GM, Kim SH. Utility of homeostasis model assessment of beta cell function in predicting diabetes in 12,924 healthy Koreans. Diabetes Care. 2010; 33: 200-202.

35. Bonora E, Targher G, Alberiche M, et al. Homeostasis model assessmen closely mirrors the glucose clamp technique in the assessment of insulin sensitivity: studies in subjects with various degrees of glucose tolerance and insulin sensitivity. Diabetes Care 2000; 23:57-63.

36. Jensen CC, Cnop M, Hull RL, et al. Beta-cell function is a major contributor to oral glucose tolerance in high risk relatives of four ethnic groups in the U.S. Diabetes. 2002; 51: 2170-2178.

37. Stancakova A, Javorsky M, Kuulasmaa $\mathrm{T}$, et al. Changes in insulin sensitivity and insulin release in relation to glycemia and glucose tolerance in 6, 414 Finnish men. Diabetes. 2009; 58: 1212-1221.

38. Festa A, Williams K, Hanley AJ, et al. Beta-cell dysfunction in subjects with impaired glucose tolerance and early type 2 diabetes: Comparison of surrogate markers with first-phase insulin secretion from an intravenous glucose tolerance test. Diabetes. 2008; 57 (6): 1638-44.

39. Tripathy D, Carlsson M, Almgren $\mathrm{P}$, et al. Insulin secretion and insulin sensitivity in relation to glucose tolerance. Diabetes. 2000; 49: 975-980.

40. Yeni-Komshian H, Carantoni M, Abbasi F, et al. Relationship between several surrogate estimates of insulin resistance and quantification of insulin-mediated glucose disposal in 490 healthy nondiabetic volunteers Diabetes Care. 2000; 23: 171-175.

41. Snehalatha C, Satyavani K, Sivasankari S, et al. Insulin secretion and action in different stages of glucose tolerance in Asian Indians. Diabet Met. 1998; 16(5): 408-14.

42. Ali A, Azim W. Insulin resistance and insulin secretion at varying levels of glucose. Pakistan Armed Force Medical Journal. ISSN 0030-9648.2010; 2.

43. Ning F, Qiao Q, Tuomilehto J, et al. Does abnormal insulin action or insulin secretion explain the increase in prevalence of impaired glucose metabolism with age in populations of different ethnicities? Diabetes Metab Res Rev. 2010; 26: 245-253.

44. Marx N, Walcher D, Raichle C, et al. C-peptide colocalizes with macrophages in early arteriosclerotic lesions of diabetes subjects and induces monocyte chemotaxis in vitro. ArteriosclerThrombVasc Biol. 2004; 24: $540-545$

45. Ford ES. Body mass index, diabetes and $C$ reactive protein among US adults.Diabetes Care. 1999; 22: 1971-1977.

46. Festa A, D' Agostino RJ, Tracy RP, et al. Elevated levels of acute phase protein and plasminogen activator inhibitor-1 predicts the development of type 2 diabetes. Diabetes. 2002; 51: 1131-1137.

47. Vikram NK, Misra A, Dwivedi M, et al. Correlation of CRP levels with anthropometric profile,percentage of body fat and lipids in healthy adolescents and young adults in urban North India. Atherosclerosis. 2003, 168: 305-313.

48. Wopereis S, Rubingh CM, Erk MJV, et al. Metabolic profiling of the response to an oral glucose tolerance test detects subtle metabolic changes. PloS ONE. 2009; 4: 1-13. 